\title{
FUNCTIONAL ACTIVITY OF CD34-POSITIVE CELLS IN CHRONIC MYELOID LEUKEMIA PATIENTS WITH DIFFERENT RESPONSE TO IMATINIB THERAPY
}

\author{
I.O. Sviezhentseva', T.P. Perekhrestenko ${ }^{2}$, D.I. Bilko', A.I. Gordienko ${ }^{2}$, M.V. Diachenko', I.S. Dyagil ${ }^{3}$ \\ ${ }^{1}$ Centre for Molecular and Cell Research of National University of "Kyiv-Mohyla Academy", Kyiv 04655, Ukraine \\ ${ }^{2}$ SI "Institute of Hematology and Transfusiology of the NAMS of Ukraine", Kyiv 04060, Ukraine \\ ${ }^{3} S I$ "The National Research Center for Radiation Medicine of the NAMS of Ukraine”, Kyiv 04050, Ukraine
}

Introduction: It is believed that the reason of the leukemic clone cell resistance to treatment with tyrosine kinase inhibitors during chronic myeloid leukemia (CML) is mutations in the genome of an early bone marrow progenitor cells that are CD34-positive. Such cells, regardless of treatment, acquire ability to proliferation and differentiation. This leads to the re-expansion of the $\mathrm{CD}^{+} 4^{+}$cells. Aim: to determine the CD34 antigen expression in bone marrow and peripheral blood cells in CML patients with different response to imatinib therapy using the results of hematopoietic cells culturing and the data of flow cytometry. Methods: Bone marrow aspirate from 39 patients who were treated with imatinib was studied with cytogenetic, flow cytometry and culture methods in vitro. Results: In patients with an optimal response to imatinib therapy the number of colonies was 1.8 times lower than the number of those in the group of patients with a suboptimal response to therapy. In turn, in patients with failure of imatinib therapy the number of colonies was the highest and was 2.1 times higher than the patients with optimal response. The results of cytometric studies have shown that the number of $\mathrm{CD34}^{+}$cells in bone marrow was significantly higher compared to the number of $\mathrm{CD}^{+} 4^{+}$cells in peripheral blood cells and increased with the acquisition of leukemic cells the resistance to imatinib. There was a direct correlation between the number of colonies and clusters in semisolid agar in vitro and the number of $\mathrm{CD}^{+} 4^{+}$cells in the bone marrow of patients. Conclusions: The correlation between the number of $\mathrm{CD34}^{+}$cells and the number of cell aggregates in semisolid agar in vitro indicates the prognostic value of the method for determining $\mathrm{CD34}^{+}$cells in the patient bone marrow. The parallel increase of their number in the peripheral blood will allow developing express methods for the detection of individual patient response to imatinib therapy.

Key Words: chronic myeloid leukemia, imatinib, cell culture in vitro, $\mathrm{CD}^{+} 4^{+}$cells.

Chronic myeloid leukemia $(\mathrm{CML})$ is a myeloproliferative neoplasm that characterized the expansion of the early hematopoietic progenitor cells pool which express CD34 antigen $[1,2]$. It is known that the differentiation of bone marrow cells expression of CD34 antigen on the cell surface of myeloid hematopoiesis decreases or disappears [3]. In general, the function of CD34 antigen is still not clear, but it is believed that it plays an important role in the interaction between hematopoietic cells and bone marrow microenvironment $[4,5]$.

The cause of CML is tyrosine kinase activity of BCR$A B L$ oncoprotein, which is expressed by derivative chromosome 22. It is called the Philadelphia chromosome (Ph-chromosome) [6]. Due to the aforementioned activity of this oncoprotein the leukemic clone cell is not only characterized by altered potential for self-renewal and differentiation, but also by the reduced the levels of adhesion to bone marrow stroma. As a result a large number of early CD34-positive hematopoietic cells get to the peripheral blood $[7,8]$.

The BCR-ABL tyrosine kinase is a therapeutic target of the imatinib which is the first-generation of tyrosine kinase inhibitors (TKI) [9]. Early clinical studies have revealed that $65-85 \%$ of patients had a complete cytogenetic remission received after 12 months of imatinib therapy which was much more effective compared

Submitted: November 06, 2014.

‘Correspondence: Email: iilona@ukr.net; tat2007@bigmir.net Abbreviations used: CFU-GM - colony-forming unit-granulocyte/ macrophage; CIFU - cluster-forming unit; CML - chronic myeloid leukemia; TKI - tyrosine kinase inhibitors. to other therapeutic agents, known at that time. However, a part of the patients (approximately $30 \%$ ) did not achieve a complete cytogenetic response within 1 year of treatment [10]. Some researchers consider that the resistance is caused by mutations in the genome of bone marrow progenitor cells that are CD34-positive. Such cells, regardless of treatment, get on ability to active proliferation and differentiation. This leads to the reexpansion of the pool of CD34+ cells [3]. That is why immunophenotypic monitoring of $\mathrm{CD} 34^{+}$cells in peripheral blood and bone marrow should be conducted for the prognosis of the disease and evaluation of the effectiveness of therapy in CML patients $[11,12]$.

The aim of this work was to determine the features of CD34 antigen expression in bone marrow and peripheral blood in CML patients with different response to imatinib therapy using the results of hematopoietic cells culturing and the data of flow cytometry.

\section{MATERIALS AND METHODS}

We studied the bone marrow samples of $39 \mathrm{CML}$ patients during the chronic phase of disease treated with imatinib for at least 12 months. The average age of patients was $54.0 \pm 7.41$ years. All patients before the study signed a voluntary informed consent. All patient sampleswere obtained under Research Ethics Board. According to the criteria for assessing the effectiveness of tyrosine kinases therapy of The European LeukemiaNet the patients were divided into three groups: with optimal $(n=15)$, suboptimal response $(n=10)$ and failure $(n=14)$ of the imatinib therapy. The optimal response means a complete cyto- 
genetic response after 12 months of therapy with imatinib ( $0 \% \mathrm{Ph}$-positive cells). Suboptimal response was defined when the bone marrow research showed from 1\% to 35\% of Ph-positive cells after 12 months of imatinib therapy. The lack of response to the drug indicated the presence of a large number of cells with Ph-chromosome, which is greater than $35 \%$ in the bone marrow [13].

To determine the functional activity of hematopoietic cells of patients in vitro culturing of bone marrow mononuclear cells in semisolid agar ("Difco", USA) (concentration $0.33 \%$ ) with a use of the medium for culturing RPMI-1640 ("Sigma", USA), 20\% fetal calf serum and antibiotics (50 IU/ml penicillin, $50 \mathrm{mg} / \mathrm{ml}$ streptomycin) was carried out. Cultivation was performed for 13 days under conditions of absolute humidity, $5 \% \mathrm{CO}_{2}$ and at $37^{\circ} \mathrm{C}$. A cluster-forming units included no more than 40 cells, at the same time the colony consists of from 40 to several hundred cells (Fig. 1). A proliferative potential was determined as the ratio of the number of colonies and the number of clusters.
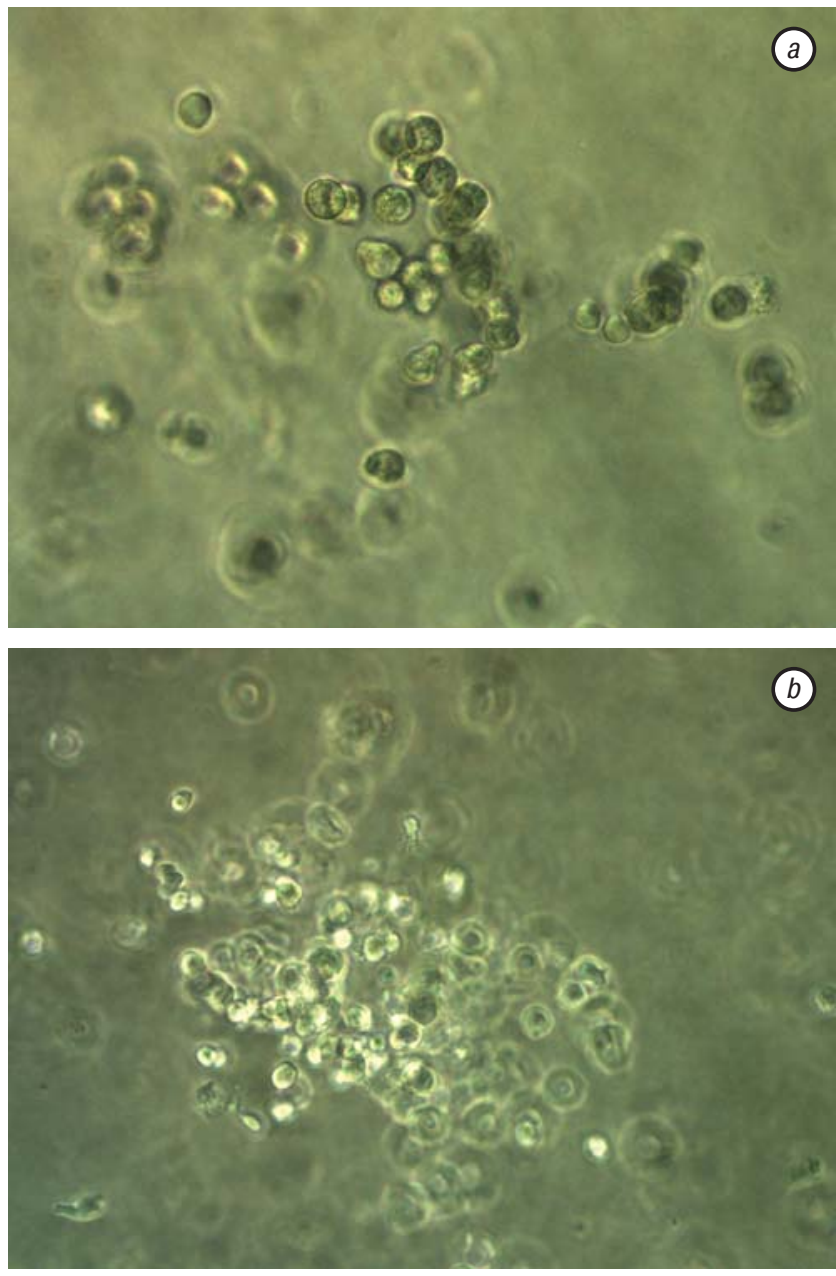

Fig. 1. Colony ( $a$ ) and cluster $(b)$ formed by culturing bone marrow cells of patients with $\mathrm{CML}$ in vitro

To assess the phenotypic characteristics of hematopoietic cells of patients the method of direct flow cytometry was used. For this purpose, bone marrow mononuclear cells were stained with monoclonal antibodies ("Becton Dickinson", USA) using the method provided by the manufacturer. Flow cytometry study was performed using a flow cytometer laser FACScan ("Becton Dickinson", USA) with an argon laser which has a wavelength of $488 \mathrm{~nm}$.
Data collection was performed by flow cytometry using the LYSYS-II Ver. 1.1 ("Becton Dickinson", USA) software. The program WinMDI 2.8 (Joseph Trotter, Scripps Institute, La Jolla, CA) was used to analyze the results.

The statistical analysis of the results was carried out using nonparametric Mann - Whitney tests for comparing two populations. The conclusion of the statistical significance of the results made at $p<0.05$. For estimation of interrelations between obtained indexes the correlational analysis with determination of Pearson's correlation coefficient has been conducted.

\section{RESULTS AND DISCUSSION}

In general, the determination of the number of colonies in semisolid agar in vitro is used as a test system to check the impact of chemotherapeutic agents on the leukemic clone cells [14]. However, such studies are usually implemented under conditions of the presence of chemotherapeutic agents in the culture medium. Culture of bone marrow subjected to therapy with $\mathrm{TKI}$ and with the absence of imatinib in the cultivation medium may allow reproducing the features of bone marrow cells proliferation without the inhibitory effect of the drug. The previous studies have demonstrated that the determination of functional activity of bone marrow cells of CML patients in semisolid agar in vitro with different response to imatinib therapy may have prognostic value for assessing the further development of the disease $[15,16]$. However, a problem of finding the predictive test systems that would be efficient and quick remains open. Therefore, it appeared reasonable to compare the results of cultivation with the number of cells expressing CD34 antigen.

The results of cultivation suggest that in patients with an optimal response to imatinib therapy the number of colonies was 1.8 times lower than the number of those in the group of patients with suboptimal response to therapy (Table 1). In turn, in patients with failure of imatinib therapy the number of colonies was the highest and was 2.1 times higher than the patients with optimal response. In the case of clusters was recorded tendency to increase this indicator in patients with suboptimal response and treatment failure. In addition, the patients with inefficiency and suboptimal response to imatinib therapy had the significantly higher proliferative potential than in patients with optimal response. This may indicate that early progenitor cells dominated the more differentiated cells which form clusters in the culture. In turn, in the bone marrow of patients who have increasing numbers of leukemic clone cells proliferation processes dominate over the processes of differentiation that may be the cause of the increase of the number of colonies in semisolid agar in vitro [17].

Table 1. Characteristics of the functional activity of bone marrow cells in patients with different response to imatinib therapy

\begin{tabular}{lccc}
\hline \multicolumn{1}{c}{ The response } & $\begin{array}{c}\text { The number } \\
\text { to imatinib therapy }\end{array}$ & $\begin{array}{c}\text { The number } \\
\text { of colonies }\end{array}$ & $\begin{array}{c}\text { Proliferative } \\
\text { potential }\end{array}$ \\
\hline Optimal response & $34.42 \pm 1.46$ & $46.01 \pm 2.27$ & $0.94 \pm 0.04$ \\
Suboptimal response & $63.75 \pm 2.57^{*}$ & $54.25 \pm 4.68$ & $1.19 \pm 0.02^{\star}$ \\
Failure of the therapy & $73.81 \pm 3.2^{*}$ & $54.53 \pm 3.7$ & $1.41 \pm 0.05^{\star}$ \\
\hline
\end{tabular}

${ }^{*}$ Statistically significant differences with group of optimal response $(p<0.05)$. 
The results of cytometry analysis showed that in patients with the acquisition of resistance to imatinib the number of $\mathrm{CD} 34^{+}$cells increases in the bone marrow and peripheral blood (Table 2). It should be noted, in patients with different response to therapy the number of CD34 antigen in bone marrow and peripheral blood was significantly different. This may indicate that during the progression of CML and during the acquisition of resistance to the drug by leukemic clone cells the pool of early progenitor cells not only expands, but also, due to the weakening of contacts between the cells of the microenvironment and leukemic clone cells, the early progenitor cells fall in blood flow in large numbers, promoting a poorly differentiated hematopoietic cells in peripheral blood of patients [5].

Table 2. Expression of CD34 antigen on hematopoietic progenitor cells in the bone marrow and peripheral blood of CML patients with different response to imatinib therapy $(\% \pm \mathrm{m} \%)$

\begin{tabular}{lcc}
\hline \multicolumn{1}{c}{ The response } & The number of CD34 & The number of CD34 \\
to imatinib therapy & bone marrow cells & peripheral blood cells \\
\hline Optimal response & $9.23 \pm 2.01$ & $4.43 \pm 1.07$ \\
Suboptimal response & $31.65 \pm 5.85^{\star}$ & $12.08 \pm 5.35^{\star}$ \\
Failure of the therapy & $44.37 \pm 6.72^{\star}$ & $17.95 \pm 4.42^{\star}$ \\
\hline
\end{tabular}

*Statistically significant differences with group of optimal response $(p<0.05)$.

A correlation analysis was conducted to identify the correspondence between the number of $\mathrm{CD} 34^{+}$cells in the bone marrow and in peripheral blood of patients treated with imatinib. These results indicate a direct correlation between the number of colonies and clusters in semisolid agar in vitro and the number of CD34 ${ }^{+}$cells in the patient bone marrow $(r=0.83$ and $r=0.58, p<0.05)($ Fig. 2).
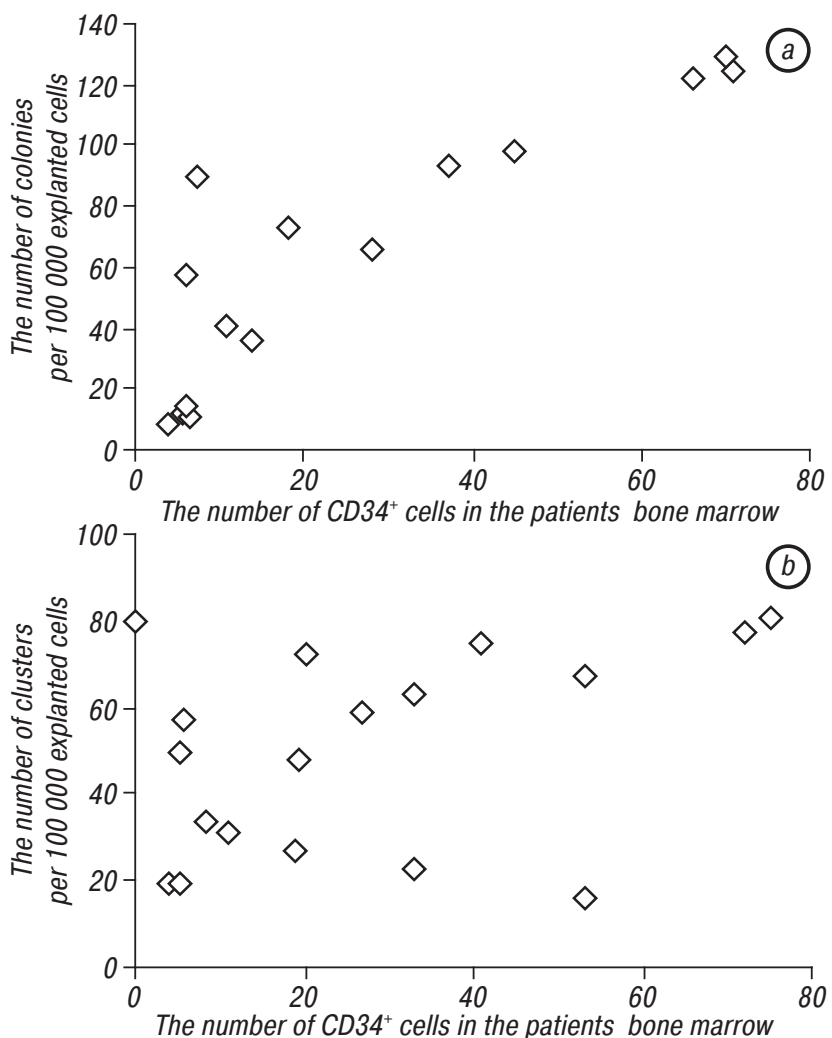

Fig. 2. Correlation between number of $C D 34^{+}$cells in the patients bone marrow, the number of colonies $(a)$ and the number of clusters $(b)$

Thus, the number of $\mathrm{CD} 34^{+}$cells in the bone marrow of patients increases with the acquisition of leukemic clone cells resistance to imatinib. The correlation between the number of $\mathrm{CD} 34^{+}$cells and the number of cell aggregates in semisolid agar in vitro, which may be predictive method for determining the future course of CML, shows the prognostic value of method for determining the CD34 ${ }^{+}$ cells in the bone marrow of patients; and a parallel increase of their number in the peripheral blood of patients will allow to develop express methods for the detection of individual patient response to imatinib therapy.

\section{REFERENCES}

1. Goldman JM, Melo JV. Chronic myeloid leukemia advances in biology and new approaches to treatment. New Engl J Med 2003; 349: 1451-64.

2. Frazer R, Irvine AE, McMullin MF. Chronic myeloid leukaemia in the $21^{\text {st }}$ century. Ulster Med J 2007; 76: 8-17.

3. McWeeney SK, Pemberton LC, Loriaux MM, et al. A gene expression signature of $\mathrm{CD} 34^{+}$cells to predict major cytogenetic response in chronic-phase chronic myeloid leukemia patients treated with imatinib. Blood 2010; 115: 315-25.

4. Faderl S, Talpaz M, Estrov Z, et al. The biology of chronic mieloid leukemia. New Engl J Med 1999; 15: 164-72.

5. Konopleva MY, Jordan CT. Leukemia stem cells and microenvironment: biology and therapeutic targeting. J Clin Oncol 2011; 29: 591-9.

6. Bacco AD, Keeshan K, McKenna SL, et al. Molecular abnormalities in chronic myeloid leukemia: deregulation of cell growth and apoptosis. The Oncologist 2000; 5: 405-15.

7. Marley SB, Gordon MY. Chronic myeloid leukaemia: stem cell derived but progenitor cell driven. Clin Science 2005; 109: 13-25.

8. Donato NJ, Peterson LF. Chronic myeloid leukemia stem cells and developing therapies. Leuk Lymphoma 2011; 52: $60-80$.

9. Mughal A, Aslam HM, Khan HAM, et al. Bcr-Abl tyrosine kinase inhibitors-current status. Infect Agents Cancer 2013; 8: 1-3.

10. Jabbour E, Cortes JE, Kantarjian HM, et al. Suboptimal response to or failure of imatinib treatment for chronic myeloid leukemia: what is the optimal strategy? Mayo Clin Proc 2009; 84: 161-9.

11. Corbin AS, Agarwal A, Loriaux M, et al. Human chronic myeloid leukemia stem cells are insensitive to imatinib despite inhibition of BCR-ABL activity. J Clin Invest 2011; 121: 396-409.

12. Diaz-Blanco E, Bruns I, Neumann F. Molecular signature of $\mathrm{CD}_{3} 4^{+}$hematopoietic stem and progenitor cells of patients with CML in chronic phase. Leukemia 2007; 21:494-504.

13. Baccarani M, Saglio G, Goldman J. Evolving concepts in the management of chronic myeloid leukemia: recommendations from an expert panel on behalf of the European Leukemia Net. Blood 2006; 108: 1809-20.

14. Mayani H, Flores-Figueroa E, Chavez-Gonzalez A. In vitro biology of human myeloid leukemia. Leuk Research 2009; 33: 624-37.

15. Dyachenko MV, Bilko DI, Dyahil IS, et al. Patent of Ukraine № 83862. The method of evaluation of the disease in chronic myeloid leukemia from 05.09.13. Official Bulletin "Industrial Property" 2013: 18 (in Ukrainian).

16. Bilko D, Zhaleiko I, Perekhrestenko T, et al. The determination of the relapse risk of CML Patients using the indicators of the functional activity of bone marrow and index sokal. Ach Biol Medicine 2014; 1: 28-31 (in Ukrainian).

17. Eaves AG, Eaves AC. Stem cell kinetics. Baillires Clin Haematol 1997; 10: 233-57. 